\title{
(息)
}

Citation:

Flintoff, A (2008) Targeting Mr Average: Participation, gender equity and school sport partnerships. Sport, Education and Society, 13 (4). 393 - 411. ISSN 1357-3322 DOI: https://doi.org/10.1080/13573320802445017

Link to Leeds Beckett Repository record:

https://eprints.leedsbeckett.ac.uk/id/eprint/362/

Document Version:

Article (Accepted Version)

The aim of the Leeds Beckett Repository is to provide open access to our research, as required by funder policies and permitted by publishers and copyright law.

The Leeds Beckett repository holds a wide range of publications, each of which has been checked for copyright and the relevant embargo period has been applied by the Research Services team.

We operate on a standard take-down policy. If you are the author or publisher of an output and you would like it removed from the repository, please contact us and we will investigate on a case-by-case basis.

Each thesis in the repository has been cleared where necessary by the author for third party copyright. If you would like a thesis to be removed from the repository or believe there is an issue with copyright, please contact us on openaccess@leedsbeckett.ac.uk and we will investigate on a case-by-case basis. 
Targeting Mr Average: Participation, Gender Equity, and School Sport Partnerships

\author{
Anne Flintoff \\ Leeds Metropolitan University \\ Forthcoming, Sport, Education and Society Journal \\ 2008
}

Contact:

Dr Anne Flintoff,

Carnegie Research Institute,

Leeds Metropolitan University,

Fairfax Hall,

Headingley Campus,

Leeds LS6 3QS

Tel: 01132832600

Fax 01132833201

Email: a.flintoff@leedsmet.ac.uk 
Targeting Mr Average: Participation, Gender Equity, and School Sport Partnerships

\begin{abstract}
:
The School Sport Partnership Programme (SSPP) programme is one strand of the national strategy for PESS in England, the PESS Club Links Strategy (PESSCL). The SSPP aims to make links between school PE and out-ofschool sports participation, and has a particular remit to raise the participation levels of several identified under-represented groups, of which girls and young women are one. National evaluations of the SSPP show that it is beginning to have positive impacts on young people's activity levels, through increasing the range and provision of extra curricular activities (Loughborough Partnership, 2005; 2006; Office for Standards in Education (OFSTED) 2003; 2004; 2005). This paper contributes to the developing picture of the phased implementation of the programme by providing qualitative insights into the work of one school sport partnership with a particular focus on gender equity. The paper explores the ways in which gender equity issues have been explicitly addressed within the 'official texts' of the SSPP; how these have shifted over time and how teachers are responding to and making sense of these in their daily practice. Using participation observation, interview and questionnaire data, the paper explores how the coordinators are addressing the challenge of increasing the participation of girls and young women. The paper draws on Walby's (2000) conceptualisation of different kinds of feminist praxis to highlight the limitations of the coordinators' work. Two key themes from the data and their implications are addressed: the dominance of competitive sport practices, and the PE professionals' views of targeting as a strategy for increasing the participation of under-represented groups. The paper concludes that coordinators work within an equality or difference discourse with little evidence of the transformative praxis needed for the programme to be truly inclusive.
\end{abstract}




\section{Targeting Mr Average: Participation, Gender Equity, and School Sport Partnerships}

\section{Introduction}

This is arguably a period of significant change for those involved in physical education (PE) and school sport in England. The phased implementation of a national strategy is transforming the infra structure of PE and school sport through a number of inter-linked policy initiatives. With schools at the centre, it aims to create a coherent framework for PE and youth sport. The PE and School Sport Club Links Strategy (PESSCL) (Department for Education and Skills (DfES) /Department for Culture, Media and Sport (DCMS), 2003) ${ }^{1}$, as its name suggests, seeks to develop links and partnerships - between schools, between groups of schools and wider community sports agencies and networks, and between PE and sport. The different initiatives in the strategy aim to improve both the range and quality of opportunities for young people to be physically active.

In phasing its implementation, it has taken over six years for every school to be incorporated into a school sport partnership. Although Kirk (2005) laments the lack of an apparent underpinning research base, a substantial programme of evaluation is exploring the ongoing impact of the strategy (e.g. Loughborough Partnership, 2005, 2006; Quick and Goddard, 2004; Houlihan and Wong, 2005), and changes and adaptations are been made to the programmes as implementation proceeds across different groups of schools. This paper aims to contribute to that developing evaluative picture, and focuses on the School Sport Partnership Programme (SSPP), with a particular focus on gender equity issues ${ }^{2}$

National evaluations of the SSPP show it is beginning to have positive impacts on PE and sport in schools (Loughborough Partnership, 2005; 2006; Office for Standards in Education (OFSTED) 2002; 2003; 2004; Quick and Goddard, 2004). For example, the programme is helping to extend the range and provision of extra curricular activities, and increase the numbers of young people who are physically active. In contrast to these survey or 'snap shot' evaluations, this paper draws on data collected from a qualitative case study of one school sport partnership over its first three years. Drawing on Penney and Evans (1999) - it uses a conception of policy as a relational activity, as a process in which individuals are differently positioned within and influenced by dominant discourses of PE and school sport. In particular, the paper is interested in exploring the ways in which gender equity issues have been explicitly addressed within the 'official texts' of the SSPP; how these have shifted over time and how teachers are responding to and making sense of these in their daily practice. The paper aims to provide a critical analysis of the nature of the physical activity opportunities provided within one school sport partnership.

\section{Gender Equity in PE and School Sport}


Over the last three decades, there have been significant theoretical shifts and developments in the conceptualisation of gender equity in education and PE (see Skelton, Francis and Smulyan, 2006; Penney, 2002a; Penney, 2002b; Flintoff and Scraton, 2006). Theories have developed from viewing girls as a homogeneous group to ones that recognise diversity between girls, and the interconnections of gender, sexuality, race and class. In addition, studies recently have begun to explore the ways in which gender impacts on boys' experiences too (Bramham, 2004; Martino and Pallotta-Chairolli, 2003; Parker, 1996; Skelton, 2001). Whilst welcomed, these developments have created new challenges for feminism - for theory and practice. How can we acknowledge the differences that exist between girls, and yet at the same time, recognise and challenge the continuing inequalities resulting from the structures of gender, class, and 'race'? (Archer, et al 2001; Hargreaves, 2004, Walby, 2000)? If girls have different experiences of PE, what strategies should we use to address these and the continuing inequities that girls as a group continue to face? As post structural theories have led to the questioning of concepts such as girl/boy, woman/man, and to the recognition of femininities and masculinities in PE (Azzarito and Solomon, 2005), so it becomes more difficult to easily apply these insights to everyday practice (Penney and Evans, 2002).

Some authors have suggested that the shift in feminist theoretical work towards difference and diversity has not just risked its specific application to practice, but also its link to inequality and power (Hargreaves, 2004; Walby, 2000). As Flintoff and Scraton (2005) have argued, the majority of feminist praxis in PE falls into what Walby (2000) has called a politics of equality, or politics of recognition. Accounting for difference by adopting a politics of equality entails teachers working with the assumption that the current practice of PE is acceptable for girls, and all we have to do is to make the provision a bit more 'girl-friendly' by making minor changes and adaptations. Similarly, there are problems with accounting for difference by taking a politics of recognition approach. Here there is a move to develop respect for different groups, (for example, girls) with the assumption being that they have different needs and interests that are not shared with other children (for example, boys). The problem with such an approach, Walby (2000) argues, is that by simply embracing difference, existing inequalities may be endorsed. For example, the introduction of curriculum activities to meet 'girls' interests', such as aerobics, or keep fit, does little to challenge the higher status of so called 'boys' activities'.

In the same way, sports development's use of targeting, particularly in the 1979s and 1980s, as a strategy aimed at increasing participation of underrepresented groups, draws on these same political positions. Whilst not without its strengths (see White, 1997), like attempts to make PE more 'girlfriendly', targeting in sports development carries the same disadvantages: the groups identified are often too large, and are wrongly assumed to be homogenous; it suggests that the problem is with the targeted group rather than with the sport on offer, and the focus is on participation of these groups, rather than broader issues of equity in the structure and culture of sports organisations. Recently, targeting has given way to more holistic equity- 
based approach with the subsequent development of an Equity Framework and Standard (White 1997; Sport England, 2004). It is now compulsory for all government-funded sports clubs and organisations to work their way through the Equity Standard, to ensure equity principles underpin all that they do.

Walby (2000) argues that rather than a politics of equality or difference, we should adopt a politics of transformation. This approach embraces difference without losing the explicit link to inequality. Such transformative politics would ask what kind of PESS do we want for all young people, boys as well as girls? How should gender equity permeate and impact on all our practice in PE, so that all girls and boys have a quality experience?

Theoretically, this paper is located within these developing feminist theoretical debates, but, also, importantly, draws on empirical data about school sport coordinators' experiences of implementing the SSPP. How do coordinators provide PE and school sport opportunities for all? As will be seen below, the programme has shifted its policy position on equity as it has developed, from specific targeting to a permeation model. This paper is interested in highlighting this change and exploring how, if at all, these shifting positions have impacted on the coordinators' work. The next section explores some of the main features of the programme in order to describe the policy context of their work.

\section{The School Sport Partnership Programme}

The SSPP aims to create a more coherent structure of sporting opportunities for young people and to raise the quality and status of PE and school sport. The programme involves a number of schools working together in a local partnership, with (usually) a Specialist Sports College acting as the lead school $^{3}$. The Specialist Sports College works with between four and eight local secondary schools, together with their associated families of primary schools, to implement the key objectives of the programme. Partnerships strive to develop networks and opportunities between school PE and wider community leisure and sport contexts (see Youth Sport Trust (YST), 2005; Flintoff, 2003 for more details).

There are a lot of positive features about the SSPP programme for helping young people, including girls and young women, adopt and sustain active leisure lifestyles. First, the programme is grounded in local partnerships in local contexts. As Collins and Buller's (2000) evaluation of an earlier, youth sport initiative, the Champion Coaching Scheme, discovered that having the programme based at local facilities is important if pupils from socioeconomically deprived backgrounds are to be attracted. Secondly, PE teachers, who work with young people every day, are driving the programme and acting as the coordinators. This should help to ensure that activities are appropriate and educational in the broadest sense (one of the aims of the programme is that it contributes to youngsters' wider educational development, not just PE and sport). Thirdly, and importantly, a key aim of the programme is to increase the activity levels of previously underrepresented groups. In the original coordinators' handbook, four target 
groups were named: girls and young women; ethnic minority youth, disabled young people, and those from socio economically deprived backgrounds, with suggestions about how SSCos could work positively to include these youngsters (YST, 2000). There was, however, little or no recognition in this advice of the young people's multiple identities and the complex inter-relations between 'race', gender, class and ability.

Since its inception in 2000, the programme has changed significantly as other youth sport policies have emerged during its phased implementation. During the last five years, a key shift in emphasis within the youth sport agenda has been the recognition that to increase the number of opportunities available to young people is not enough and that these opportunities have to provide high quality experiences. This requirement is now specified in a government's Public Service Agreement for the national strategy, which was recently extended in December 2004. The Public Service Agreement outlines the commitment 'to provide opportunities for four hours of high quality PE, within and beyond the curriculum, for all pupils by 2010' (DfES/DCMS, 2007). In one of the latest documents to emerge as part of the national strategy - High Quality PE and Sport for Young People (DfES/DCMS, 2004) - three principles of high quality PE and sport are defined:

- Enable all young people, whatever their circumstances or ability, to take part in and enjoy PE and sport.

- Promote young people's health, safety and well being.

- Enable all young people to improve and achieve in line with their age and potential (DfES/DCMS, 2004, p1).

In light of this, new outcomes have been written for the programme with an emphasis on high quality (see below).

1. Increased participation in high quality PE.

2. Increased participation in high quality informal activity (e.g. playground).

3. Increased participation in high quality out of school hours learning.

4. Increased participation in high quality competition and performance.

5. Improved attitude, behaviour and attendance in PE, sport and whole school.

6. Increased attainment and achievement in and through PE, out of school hours learning and sport.

7. Increased participation in community based sport.

(YST, 2005)

It is interesting to note the differences between these and the original outcomes for the programme. As well as stressing the importance of highquality experiences, the new objectives also specify a clearer distinction between kinds of participation sought. PE is distinguished from out of school hours learning, and participation in informal physical activity is recognized as one important outcome, alongside participation in competition and performance. Significantly for this paper, the original outcome relating to 
increased participation of under-represented groups has been omitted in this reworking, as well as the specific link between improved students' motivation and attitude to their achievements in all aspects of school (see Flintoff, 2003).

These changes to the programme illustrate the importance of conceptualizing policy as a process (Penney and Evans, 1999). In assessing the implementation of the SSPP in the Northbridge partnership, the coordinators' actions have to be understood, in part, as a reflection of dominant (and shifting) discourses of contemporary PE and sport, into which the programme is embedded. The SSPP is far from introduced into what Houlihan (2000, p.181) calls a 'neutral policy space' but into one that 'may not only be crowded but which already possesses a pattern of power relations established as a result of an earlier policy'. The current policy context of PE is one in which a sport-based NCPE, supported by an extra curricular programme of interschool team competition, has been firmly established, particularly in the secondary schools (Penney and Harris, 1997). How then, do individual coordinators implement the SSPP within their local contexts and communities, and specifically how do they address the challenge of increasing the participation of girls and young women?

\section{The research}

This paper draws on data collected as part of a three year study of the implementation and effectiveness of one partnership situated in the North of England, 'Northbridge', in a large, multi-ethnic local education authority, 'Collingham'. The names used in the paper are pseudonyms. At the time of the research, the Northbridge partnership consisted of six secondary schools (one of which was a sports college). Each worked closely with their cluster of feeder primary schools (thirty seven primary schools in total). It is important to note here that the Northbridge partnership is very differentiated. The partnership includes very different schools within its remit - in size, characteristics of pupil intake, and facilities and resources for PE. So whilst this research has identified a number of common issues and themes underpinning the work of the partnership as a whole, each coordinator works within very different work environments in their individual cluster of schools (a secondary school and its associated feeder primary schools). In addition, the coordinators are very different in their philosophies and views of the purposes of the programme.

I was able to gain access to the activities of the partnership through my relationships and links with staff at the sports college, particularly the director of PE and sport, who negotiated for me to become a consultant to the college, and act as a 'critical friend'. Working with the PE staff, this position entailed instigating a number of evaluations of selected sports college initiatives, including the SSPP, with the overall aim of improving practice. An extensive amount of data was collected over the three years, including observations from the first year's monthly partnership meetings, and interviews conducted with the Partnership Development Manager (the teacher in the role of overall manager of the partnership) and all the coordinators at the end of the first and second years of the partnership. Questionnaire data were also collected from 
pupils and Primary Link Teacher (the primary teacher with subject responsibility for $\mathrm{PE}$ ) from the twelve primary feeder schools linked to the sports college. In addition, six primary link teachers were interviewed about their initial views of the programme. The partnership's three year development plan, annual revisions and reviews of progress, including formal feedback from OFSTED and the New Opportunities Fund that funded some out of school hours learning programmes, were also available for analysis.

This paper draws on the teacher and document analysis data specifically, rather than that gathered from the pupils. The interviews were taped with the teachers' consent, and key themes emerging from the data identified. Both sets of interviews aimed to explore how the partnership had developed to address the key objectives and expected outcomes of the programme. However, the first interviews also focused on the challenges for the teachers of settling into their new roles. It is important to note here, that whilst this research is helping to build an in-depth qualitative picture of Northbridge, it is not possible to generalize from these findings to the work of other partnerships or the success of the scheme nationally. Nevertheless, some of the findings presented here, mirror those reported elsewhere (Loughborough Partnership, 2005; 2006; OFSTED, 2003, 2004, 2005). This paper focuses on the delivery of the out of school hours learning programme, and specifically, teachers' perceptions of targeting, and working with girls and young women. Whilst the analysis presented here might be viewed as critical, it is important to stress that the teachers in the partnership are all committed individuals, working hard to develop the programme, and the partnership is seen by many in the local authority as one of the more successful.

\section{Findings:}

Everyone's welcome - to do more competitive sport

Two key themes emerged from the data. The first is the extent to which the existing policy agenda of sport-based PE influenced the range of activities and opportunities offered as part of the programme at Northbridge. To support the development of 'high quality PE', the coordinators' starting point was to do more of activities that form the NCPE. The hegemony of competitive sport within the curriculum was replicated in many of the out of school hours learning opportunities developed by the programme. For example, school sport competitions and festivals in each term were a major focus for development in the first year. The executive summary of Northbridge's first three year development plan identified this as a key element:

There will be a particular focus in the partnership to organise school sport on a more regionalised and cluster group basis. It is envisaged that all ages of children will benefit from the various festivals, competitions, displays and leagues (pg. 4).

In addition, a 'further particular focus is to improve the coherence of sporting progression pathways' (pg. 4). In the first year, a number of factors 
contributed towards a predominance of these competitive opportunities being provided in what has traditionally been viewed as 'male' sports. First, during the research all but one of the coordinators were male, secondary trained PE teachers, and all admitted to having lower levels of skills and interest in the areas of dance and gymnastics, compared to team games ${ }^{4}$. Ossie, for example, admitted that in his first year as a coordinator, he wanted to 'lead by example'. As he was qualified and interested in soccer, cricket and basketball, these were prioritised in his early work with primary schools. Here, he took a very hands-on role, delivering most of the sessions himself. His enthusiasm and commitment to the role were unquestionable, as is the testimony to the increase in opportunities for competitive team sport that have resulted from his work. But by his own admission, he felt it was a too much of a challenge to engage some youngsters (girls or boys):

anyone who wants to come can play. There are three categories aren't there? there are the kids that have elite talent, and represent school teams, kids that aren't good enough to take part in school teams and then those that don't want to participate....can we capture any of the last group? Not yet, I think that you would have to start with the first two and once you have got them in place.... It would be too ambitious to try and reach that third category. (Ossie, coordinator).

Ossie saw the development and success of the cricket and soccer teams in local leagues as a key element of his own achievements in his first year:

In [relation to the objective] school to community links, I have achieved a great deal in one or two areas... one is my own cricket club. We have started juniors from scratch, I am director of coaching, we have started two junior teams and both are at the very top of the local league which is a terrific achievement, and between them they have lost one game all season. I have yr 8 boys and girls. The other one is (name of club) Club ... for football...320 girls and boys playing ...[year] 5, 6, 7 and 9 playing on a three week cycle (Ossie, coordinator).

In addition, local professional sports clubs were proactive in offering education and community coaches to work with the children in school. So, in an early meeting with his coordinator, when the partnership development manager made a point of inviting sports development officers and community coaches from local clubs so that they could 'get to know faces', the sports represented were rugby league, rugby union and football. Rugby league and football also formed the focus of the first two in-service courses for primary teachers again, provided free, by coaches linked to the professional clubs in the area. The officers' remit also included girls' teams, but with smaller number of opportunities for women to play these sports, it was much harder to build links and develop performance pathways for interested girls and young women. In addition, the more traditional 'women's' sports of hockey or netball clubs mostly rely on volunteers for coaching and development work, with much of this work going on outside of schools hours, in the evening or at weekends. This also made linking with the work of the coordinators more difficult. The current inequitable sport structures operated, then, to restrict and constrain 
the ways in which the coordinators promoted and developed opportunities for girls and young women. As Kay (2003) notes, because sport reflects the current state of gender relations, attempts to promote girls' and women's participation and involvement are not straight forward. In addition, whilst the last three decades have seen an extensive array of programmes and initiatives aimed at increasing participation by girls and women, evaluations of these show the doubly difficult task of engaging women from disadvantaged and minority ethnic backgrounds (Kay, 2003; 2005). With a particular remit to develop school-club links, this leaves the coordinators with many issues and dilemmas. In their end of first year interview, several reflected on the limitations of developing school-club links in competitive games for raising the participation levels of the many of their pupils, particularly girls:

In my opinion, the boys are better catered for here than the girls. We have links with the local rugby club and athletics club, but ... we need to make sure that the girls are looked after as well... Some of the success at secondary school has been with some of the pupils that are not normally active ..we have had girls' football teams and rugby teams and girls' cricket. Again, next year, we are having a big push on noncompetitive games, so gym and dance, weights club, cycling club, we are moving away from the games situation to try and increase participation. We have got the same people doing the teams all the way through, and we don't hit the high percentage of the kids (Carlton, coordinator).

..a lot of clubs are geared to year 5 and year 6 [nine and ten year olds] so that is something that I would like to tackle, that we have more key stage 1 [five to seven year olds] clubs, and then, different activities, away from the games activities that would attract more or those who don't participate.. I think you will have bigger participation from those who don't normally participate by offering wider range of activities ....We have had kabbadi, orienteering, gym and a dance club that don't tend to attract the year 6 lads that are into rugby and football, so we have done quite well (Gary, coordinator).

Perhaps more significant than the content on offer is the way in which the format of selective, competitive team sport - more characteristic of the secondary schools - was implemented in primary schools. Half-termly blocks of coaching sessions in NCPE games activities often culminated with an interschool competitive 'festival' or entry into a local 'league'. This format means that only a minority of pupils (high-ability pupils) were selected to represent their school team to compete against other schools. One primary link teacher (who was also the head teacher of the school) suggested that the out of school hours football club had become more serious after entering a team in the local league - 'although we believe in $100 \%$ participation, at the end of the day, we want to win that league'. When probed, she admitted that the team was all boys, and the girls' attendance at the club had dropped off after they had not been selected to play for the team. 
They haven't been involved in the matches because ..I don't know, one might have been ...but because some of the girls have been feeling intimidated by some of the boys at football training on a Monday night, our learning mentor have now set up girls' football on a Wednesday.... His view is that they just get in the way on a Monday. So they are not particularly skilled these girls, whereas last year they were very good and they did have good ball skills and they were very involved in it all. On Wednesday, it does seem to be working and hopefully they will acquire the basic skills and go in on the Monday session....there is more awareness for girls' football now..(Toni, primary link teacher/ primary school head teacher)

Although girls were not formally excluded from attending sessions, it is not difficult to see how they might be dissuaded from continuing if they were viewed as 'getting in the way' and 'not good enough' to play for the school team. On another occasion, an attempt to support the inclusion of mixed teams in a primary football festival served to reinforce the view of girls' participation as an 'add on' or a compromise. The draft instructions to school instructions about a seven a-side tournament suggested teams should include 'at least two girls'. It was changed to a more equitable 'a minimum of two boys and two girls should be included in each team' after the original wording was challenged, and the importance of language in conveying stereotypical gendered notions of ability was pointed out (Wright, 1996) ${ }^{5}$

Given the dominant sport discourse in PE, particularly in secondary schools, it is perhaps not surprising that much of the coordinators' work was slanted towards development of competitive games activities. The Loughborough Partnership (2005) national evaluation of twenty partnerships also highlighted the increase in opportunities for girls in traditionally 'male' activities such as rugby or football. Alongside this, the formal evaluation of the programme, through the annual reporting mechanism for the YST, supports such a discourse in asking coordinators to account for the number of inter and intraschool competitions and events completed in any one year. I am not suggesting here that competitive games are inappropriate activities for children and young people. Rather I am interested in the implications of ways in which these activities are on offer, the kind of pedagogy used, and balance of activities on offer as part of the out of school hours learning programmes. Kirk (2006); Kirk and Gorely (2000) and Kirk (2005) has explored these issues in detail, and note the importance of, amongst other things, of appropriate pedagogy; teacher and coach development; the availability of appropriate pathways for different ability levels to continue with their sport involvement, and coordination through intelligent policy development. In essence, they highlight the importance of good educational and inclusive practice in youth sport experiences. However, as Kirk (2005) concludes, we have some way to go before many of our sports clubs offer the kinds of environments and experiences that he and his colleagues advocate. Nevertheless, he also recognises the potential for schools to function as local, multi-sport clubs and overcome some of the challenges of current practice. The SSPP seems to provide just such an opportunity. 
It is important to note that there were examples of good practice in Northbridge, and two in particular are worth mentioning. A woman head of PE at a secondary school chose netball as the activity to develop a sports club for year 6 (10-11year old) girls. Whilst netball was the activity focus, the club had much broader, educational goals of helping to integrate the predominantly South Asian girls from one primary school with the predominantly white girls from another, and in facilitating a smooth transition between primary and secondary school. In another example, a high-level table tennis coach, whilst clearly having the long-term aim of identifying and developing talent, delivered high-quality, differentiated sessions, as well as ensuring teachers had access to in-service training and free equipment to ensure the sustainability of her sessions. These sessions mirrored the principles of good practice outlined above, but arguably central to the success of both was the experienced and talented teacher and coach leading them.

Whilst operating inside the hegemony of competitive sport, other activities were also developed. As Penney and Evans (1999) state, there are always multiple discourses within policy texts, so whilst it could be argued that sport was the dominant discourse underpinning much of their practice, some of the coordinators recognised the importance of moving beyond this (at least in the primary schools) to deliver some of the other activity areas of the NCPE. Regular requests came from the primary link teachers for curriculum support and in-service training for dance and gymnastics, as well as other, more individually-based activities such as orienteering and cycling. The coordinators were also encouraged to do this in formal feedback about their development plan from the YST and Sport England. This specifically suggested (amongst other things) that further consideration should be given to 'the inclusion of non-competitive opportunities and targets' in the out of school hours learning provision, and ensuring that there should be 'clear targets for girls and women' and the other under-represented groups noted above (this latter point is discussed in more detail in the next section). The legitimation of alternative discourses to competitive sport through this formal communication was important in helping the coordinators reflect on their practice. Certainly, as new, non-competitive physical activity initiatives (such as Huff and Puff, a programme aimed at promoting informal physical activity in school playgrounds) were introduced to them in their partnership meetings, these were discussed and the information often passed onto the primary link teachers. However, compared to some games, setting up new development activities in other areas of the curriculum, often took more time and effort. Coaches were less easy to find, and sometimes expensive, and often it was easier simply to accept what was freely on offer. For example, although one primary link teacher had reservations about the quality of football coaching provided by the local professional club, with a lack of real alternatives, she was prepared to accept this as 'better than nothing':

sometimes you just want someone to come and work with them [the children], so sometimes it is better to have someone working with them than no one at all...(Flora, primary link teacher).

Another coordinator lamented that he was 'not supposed' to use teachers to 
deliver the out of school hours learning clubs, and yet in his mind, these were the best people, not coaches:

There is a big difference between coaching and teaching! ....The best people to run these clubs are the teachers themselves. For example, the __ football club people, for example, were appalling ....and Anne [the primary link teacher] and the other teacher watched it and said that they had not learnt anything. They wanted to know how to teach football to the girls and they were awful! They did things that were not suitable for kids that couldn't play, weren't suitable for a class of 30, they were all girls, football was not high on their priority anyway, and there were $70 \%$ Asian and they needed someone to encouraging them and stripping it back to basics... These people are used to dealing with elite athletes ...(Barry, coordinator).

Concerns about the lack of high quality delivery in extra curricular PE and school sport have been prevalent more widely in the programme. OFSTED (2004) noted that in $47 \%$ of cases, the quality of teaching in extra curricular sessions was only 'satisfactory', with a further $20 \%$ considered 'unsatisfactory', although the report the following year (OFSTED, 2005) reported a 'slightly more positive picture'. Similarly, the Loughborough Partnership (2005) noted the increase in the use of commercial companies by many partnerships who provide short block of coaching, followed by a mini tournament, and suggested that their impact be carefully evaluated.

Often it was through the request or action of an individual teacher that innovative programmes emerged. For example, one primary link teacher asked for Asian dance as part of her out of school hours learning clubs, specifically to attract the South Asian girls at her school. Another developed an orienteering club because of her own interest in the activity, providing further weight that individual biographies of teachers were significant to the kinds of programmes developed at Northbridge. So, although it could be argued that sport was the dominant discourse evident at Northbridge, there was, nevertheless, a range of activity opportunities made available for some of the pupils. As the next section explores, most of these were offered in an 'open access' format.

\section{Open to all - the illusion of equity}

Although observational data showed little evidence of equity issues being addressed generally through the Northbridge's work, the coordinators, nevertheless, were required to address targeting issues in aspects of their work not least because some of the funding relied on it. In applying for funds from the New Opportunities Fund ${ }^{6}$ to support their out of school hours learning programmes, school sport partnerships are required to identify particular groups of pupils in their development plans. Although targeting by age group seemed to readily accepted (mirroring the national evaluations that show $75 \%$ of schools use this method - Quick and Goddard, 2004), the coordinators in the Northbridge partnership considered the strategy of targeting more controversial when considering other groups. There was 
disagreement about both the fairness and feasibility of targeting as a strategy for raising the participation of under-represented groups in particular, and the out of school hours learning development plan reflected these views. The response from the funding body to Northbridge's initial proposals raised concerns about their 'uneven' approach to targeting. As a result, only six months of funding was initially agreed. Although coordinators were aware that girls were under-represented in some clubs and activities as they unfolded, most did not see targeting as the answer. For Neil, in his first year of teaching, targeting seemed unfair:

Simply by targeting people, you are excluding people right away though aren't you? I don't think you should exclude people just because they are Mr average, so all the clubs have been open...The activities we have done tend towards games activities, and now whether that is including or excluding - it is possible that is an issue...(Neil, coordinator).

Similarly, Barrie maintains that his primary link teachers were adamant that targeting was not fair:

I have a lot of problems with targeting because a lot of them will say we are here for everybody. They believe they [the OSHL activities] are there for everyone, and if you can be bothered to turn up, then they are there for everybody. It's just the way (Barrie, coordinator)

Gary stressed that whilst most of his primary link teachers are very aware of trying to include different children, in small schools, they felt targeting particular groups was impractical and unworkable:

They certainly want different activities, definitely, er...and I do think that they want other people rather than the same ones all the time. They like to spread it around a bit, but then targeting they find that quite difficult because some of them have got tiny schools, where you say target disaffected boys, then they say well that's one or that's two. They see it as a bit of just jumping through hoops. They will say we will ask these kids to go along but overall, we want it open because we only have seven in the year group, and we want it open (Gary, coordinator).

These views mirror the concerns more widely of such strategies for raising young people's participation levels in PE and sport. Evaluations of other New Opportunities Fund programmes have noted targeting as a challenge, and its purposes often misunderstood (Big Lottery Fund Research Issues 15, 2005; Shah, 2003; 2005). As well as seeing targeting as unfair as a strategy, many coordinators also felt that, despite their best efforts, it was unlikely that they were ever going to get some pupils taking an active part. They stressed that it has to be a matter of choice, and felt that some pupils, whatever efforts were made, would not be interested in PE and sport. The findings of a large, national study, evaluating the impact of out of school hours learning programmes, resonates with their misgivings. This identified a key feature of 
successful programmes was that pupils could choose whether or not to attend (MacBeath, et al, 2001). However, the report also concluded that there was a need for strategies to work with pupils who were not motivated to attend. When asked, all the coordinators and the primary link teachers agreed that they have had difficulty in attracting pupils that have not 'traditionally' been involved in the PE and sport activities, but also questioned whether there was any strategy that could include pupils who were not traditionally active. Girls were highlighted as part of this group:

....It is really difficult to keep the girls interested. You know there will always be the handful that have done everything at primary school and their parents want them to carry on and they are prepared to pick them up and so on and so forth, and....We have a netball team in every year but it is a battle to keep them coming, and they will maybe do one night a week staying behind but not more (Rosie, coordinator).

Several teachers talked about the under-representation of South Asian girls in particular:

I would say they are [under-represented]..to be honest. I mean not through lack of trying but I think quite often the strict Muslim religion, it is very much the girls go home for lunch and come back again....It depends very much on the parents obviously and how sort of westernised they are. Some of them are brilliant and some of them are very...(Rosie, coordinator).

We don't have any Asian girls staying to any after school events. The Asian boys stay for the football and the basketball. We have more girls staying for gym than boys, which is something stereotypical for girls. Basketball was very popular and that was mixed. So it is the Asian girls but I think that it because they don't particularly have an interest in the same way as the white girls.. At the end of the day, some of it is down to personal choice and some of the Asian girls don't like PE. That could be an issue about what they wear for PE, because it tends to be the older girls because they tend to wear the leggings and our girls here wear shorts for PE....We don't have changing rooms and at the moment the girls open cupboard doors and change behind those so that could be a major issue in girls wanting to take part because a lot of our Muslim girls are quite shy and culturally they are...(Toni, primary link teacher/primary head teacher)

As the above comments show, teachers recognised some equity issues in their provision. However, their practice drew on a liberal, equality discourse discussed earlier. As Ossie stressed 'I have matched everything I do for boys with one [a club] for girls'. Apart from a few exceptions, such as the Asian dance class, the approach adopted has been one of 'equal opportunities and access', and as the previous section showed, this has largely meant access into competitive sport activities. Girls were sometimes targeted, but mainly as a homogeneous group, different from boys, with some activities selected because, as the teacher above suggested, they were 'stereotypically for girls'. 
The under-representation of minority ethnic girls was framed within a discourse of cultural difference, where South Asian girls' culture and/or religion were defined as the 'problem'. This 'deficit' approach, in which minority cultures and/or particular religions are 'blamed' for the lack of involvement of Asian youngsters, has been identified in responses from PE teachers in other studies (e.g. Carroll and Hollinshead, 1993; Mcquire and Collins, 1998). These explanations rely on simplistic stereotypes and a lack of recognition of heterogeneity within the category of 'Asian girls' itself. As the (albeit few) studies that have explored the complex inter-relationships between gender, race and religion and PE participation have shown (e.g. Kay 2005; Benn, 1996; De Knop, et al, 1996), it is crucial to acknowledge both the complex and shifting nature of ethnic and gendered identities and the active struggles young women are engaged in on a daily basis. So whilst Kay's (2005) study, for example, shows that young Muslim girls' perceptions of, and opportunities for, sports participation are much more conditional on their family's support than for non-Muslim girls, this is never a straightforward process, or experienced in the same way by different individuals in different localities. The families in Kay's study deemed school sport - where girls could take part within the context of an educational environment - to be an acceptable form of sports provision within the requirements of Islam - an important finding for coordinators working within the school sport partnership programme. Both Figuero (1993) and Penney (2002a) ask us to question which differences get noted in PE, since these will impact significantly on the kinds of responses we identify as appropriate. As Figuero (1993, p.91) noted some time ago, 'relevant similarities and relevant differences should be given due recognition - while irrelevant similarities and irrelevant differences should be ignored...' Arguably, cultural and religious difference in this context was an important difference for the Northbridge teachers to acknowledge and work with when considering their practice. Instead, they largely sought to overcome the problem of the under-presentation of girls in general, and Asian girls in particular, through offering 'more of the same' PE and sport.

\section{Concluding comments}

This paper has provided a qualitative insight into the work of one school sport partnership with a particular focus on the inclusion of girls and young women. It is important to stress again that the teachers working at Northbridge were all enthusiastic and hard working, and that the partnership was considered one of the more successful in the region. Mirroring the national evaluations of the programme to date, there was no doubt that the partnership was providing more opportunities for children, including girls and young women, to be physically active, within and beyond the curriculum. However, it has shown how the scope and range of opportunities developed was limited by a competitive sport discourse, with many activities revolving around inter-school competitions in a narrow range of traditional sports. Whilst a number of girls have benefited from these - the girls' football and cricket competitions have been deemed a success for example - and no doubt enjoyed by those taking part - this provision has done little to include the vast majority of girls and young women (as well as some boys) and especially who have not already 
identified themselves as 'sporty' or interested in this particular kind of physical activity.

The research shows very little evidence of equity issues forming any significant part of the coordinators' deliberations or everyday practice. The strategy adopted by most coordinators was based on equality politics, and on access. An 'open door' policy to the same opportunities was seen as the fairest way to cater for all children. Very few of the planned PE and sport activities were specifically targeted at pupils that have been underrepresented in traditional extra curricular programmes, and indeed, there was some reluctance on the part of some coordinators to accept that this would constitute equitable practice. The more innovative programmes that did recognise different needs, such as the Asian girls' dance club, resulted from the actions of individual teachers, rather than from an underlying philosophy reflective of partnership as a whole. Similarly, there was little recognition that boys might also be very different in their physical activity interests and involvement or may share some of these with girls. Perhaps these findings should not be surprising, given the policy context in which the coordinators work. Flexible policy texts such as the SSPP, which encourage partnerships to develop their practice in ways relevant to their local needs, do allow for innovative practice, but the extent to which we could or should expect coordinators to work in ways that oppose or challenge the dominant discourses of PE and school sport is debatable. The discourse of competitive sport - an essentially masculinized discourse - is, and has been, a defining feature of PE for many years (Kirk, 2002; Penney, 2002c). And as evaluations of innovative practice has shown (e.g Nike/YST, 2000) have shown, without strong support from colleagues, and senior colleagues in particular, even small scale changes to existing practice is difficult to sustain. So whilst the changed policy outcomes and other supporting documentation such as a recent Dance Links publication (DfES/DCMS, 2005) may encourage the coordinators to think about the range of physical activity opportunities they offer, these have to be set against the recent introduction of competition managers into the partnerships (Schools Competition Developments, 2005). With a specific remit of 'managing and coordinating the planning and implementation of a programme of inter-school competition' it is difficult to see how competitive sport will not become more firmly embedded as the central form of physical activity on offer in school sport partnerships.

The research has highlighted the gap between the increasingly sophisticated feminist theorising about gender equity, and the realities of practice in PE and school sport. At best, Northbridge coordinators' practice was based on equality politics - of providing more of the same with the hope that more girls and young women will be attracted to take part. Some coordinators acknowledged that girls might have different needs to boys, and provided some targeted provision for girls, but as a homogeneous group. There was little evidence of what Walby (2000) calls transformative politics in their work. Transformative politics in PE would entail a much more fundamental questioning on the part of coordinators about the kinds of learning opportunities they create for their youngsters. The starting point would be an 
acknowledgement of, and commitment to, challenging dominant gender discourses and their impact on young people's experiences of PE and school sport. Whilst there is a growing body of knowledge that explores what this might mean in practice (e.g. Gorely, et al, 2003; Ennis, 1999; Gard, 2003), the data presented here suggests we are some way from being able to claim such a feminist praxis in PE and school sport. As the SSPP is extended to include every school in the country, it remains to be seen whether or not the programme can offer positive experiences for all.

\section{Acknowledgements:}

This paper has benefited from the feedback from my colleagues, especially Sheila Scraton, Pete Bramham, and from Michael Gard, to whom I owe thanks.

\section{NOTES}

1 The PESSCL strategy consists of a number of linked initiatives, supported by two government departments - education and sport and with a $£ 1$ billion investment (DfES/DCMS, 2003). A key strand of the strategy is the school sport partnership programme.

2 Its original name was the school sport coordinator programme. Starting in September 2000, the school sport partnership programme is an English initiative, although similar schemes exist in Scotland and Wales. For an overview of how the programme works, see YST, 2005; Flintoff, 2003.

3 Specialist sport colleges were introduced in 1997 by the Labour government, although the broader specialist schools initiative was originated by the previous Conservative government. Specialist Sports Colleges are maintained secondary schools in England that receive additional funding from the DfES to raise standards in PE and sport within its own school, in a local family of schools and in the community. To apply, schools are required to raise $£ 50,000$ from private sector sponsorship and submit a four-year development plan.

$4 \quad$ Since the last round of interview data, the partnership has expanded, and some coordinators have moved to new posts, leaving only two of the original male coordinators in the partnership.

$5 \quad$ This is an example of a (albeit small) change I was able to help facilitate in my role as a critical friend to the partnership.

$6 \quad$ The New Opportunities Fund (now called the Big Lottery Fund) provides each partnership with monies to develop a comprehensive out of school hours learning programme over three years. Partnerships submit a development plan, showing detailed breakdowns of the activities, costs, and how these activities are targeted to reach underrepresented groups such as girls and young women. 


\section{REFERENCES}

Archer, L., Hutchings, M., \& Leathwood, C. (2001) Engaging in Commonality and Difference: theoretical tensions in the analysis of working class women's educational discourses, International Journal of Sociology of Education, 11.41-62.

Azzarito, L., \& Solomon, M. (2005) A reconceptualisation of physical education: the intersection of gender/race/social class, Sport, Education and Society, 10.25-47.

Benn, T. (1996) Muslim women and physical education in initial teacher training, Sport, Education and Society, 1.5-21.

Big Lottery Fund Research Issue 15 (2005). New Opportunities in PE and Sport Evaluation Update [Internet]. London: Big Lottery Fund Research. Available from: http://www.nof.gov.uk [Accessed 22nd November 2005].

Bramham, P. (2003) Boys, masculinity and PE, Sport, Education and Society, 8.57-71.

Carroll, B., \& Hollingshead, G. (1993). Equal opportunities: race and gender in physical education: a case study, In J. Evans (Ed.), Equality, Education and Physical Education (London, Falmer), 154-169

Collins, M. F., \& Buller, J. R. (2000) Bridging the post-school institutional gap in sport - evaluating champion coaching in Nottinghamshire, Managing Leisure, 5.200-221.

Department for Education and Skills, \& Department for Culture Media and Sport (2003) Learning through PE and Sport: A guide to the Physical 
Education, School Sport and Club Links Strategy. (Nottingham, DfES Publications).

Department for Education and Skills/Department for Culture, Media and Sport (2005) Dance Links: A guide to delivering high quality dance of children and young people [Internet] (London, Crown [Accessed December 5th 2005]).

Department for Education and Skills, Department for Culture, \& Media and Sport (2004) High Quality PE and Sport for Young People (Annsely, DfES publications).

Department for Education and Skills/Department for Culture, Media and Sport (2007) The National PE and School Sport Club Links Strategy. Available from ttp://www.teachernet.gov.uk/teachingandlearning/subjects/pe/nationalst rategy/ [accessed $9^{\text {th }}$ February 2007]

De Knop, P., Theeboom, M., Wittock, H., \& De Martelaer, K. (1996) Implications of Islam on Muslim Girls' sports participation in Western Europe. Literature Review and Policy recommendations for sport promotion., Sport, Education and Society., 1.147-164.

Ennis, C. D. (1999) Creating a Culturally Relevant Curriculum for Disengaged Girls, Sport Education and Society, 4.31-50.

Flintoff, A. (2003) The School Sport Co-ordinator Programme: Changing the Role of the Physical Education Teacher?, Sport Education and Society, 8.231-250.

Flintoff, A., \& Scraton, S. (2005). Gender and Physical Education: the contribution of feminist research, British Education Research 
Association Annual Conference,. University of Glamorgan, Sept 1417th 2005.

- (2006). Girls and PE, In D. Kirk, D. Macdonald \& M. O' Sullivan (Eds.), The Handbook of Physical Education (London, Sage), 767-783

Figueroa, P. (1993). Equality, Multiculturalism, antiracism and Physical Education in the National Curriculum, In J. Evans (Ed.), Equality, Education and Physical Education (London, Falmer), 90-102.

Gard, M. (2003) Being someone else: using dance in anti-oppressive teaching, Educational Review, 55.211-223.

Gorely, T., Holroyd, R., \& Kirk, D. (2003) Muscularlity, the habitus and the social construction of gender: Towards a gender relevant physical education, British Journal of Sociology of Education, 24.429-448.

Hargreaves, J. (2004). Querying Sport Feminism: Personal or Political?, In R. Giulianotti (Ed.), Sport and Modern Social Theorists (Basingstoke, Palgrave Macmillan),

Hargreaves, J. (2007). Sport, exercise and the female Muslim body: negotiating Islam, politics and male power, In J. Hargreaves \& $\mathrm{P}$. Vertinsky (Eds.), Physical Culture, Power and the Body (London, Routledge), 74-100.

Houlihan, B. (2000) Sporting excellence, schools and sports development: The politics of crowded policy spaces, European Physical Education Review, 6.171-193.

Houlihan, B., \& Wong, C. (2005) Report on the 2004 National Survey of Specialist Sports Colleges (Loughborough, Institute of Youth Sport, Loughborough University). 
Kay, T. (2003). Gender, sport and social exclusion, In M. Collins \& T. with Kay (Eds.), Sport and Social Exclusion (London, Routledge),

— (2005). The voice of the family: influences on Muslim girls' responses to sport, In A. Flintoff, J. Long \& K. Hylton (Eds.), Youth Sport and Active Leisure: Theory, Policy and Practice (Brighton, Leisure Studies Association), 91-114

Kirk, D. (2002). Physical Education: a gendered history, In D. Penney (Ed.), Gender and Physical Education: Contemporary Issues and Future Directions (London, Routledge)

— (2005) Physical education, youth sport and lifelong participation: the importance of early learning experiences, European Journal of Physical Education, 11.pp. 239-255.

— (2006) Sport Education, Critical Pedagogy and Learning Theory: Toward an Intrinsic Justification for Physical Education and Youth Sport, Quest, 58.225-264.

Kirk, D., \& Gorely, T. (2000) Challenging thinking about the relationship between school physical education and sport performance, European Journal of Physical Education, 6.119-134.

Loughborough Partnership (2005) School Sport Partnerships: Monitoring and Evaluation Report 2004 (Loughborough, Institute of Youth Sport, Loughborough University).

— (2006) School Sport Partnerships: Annual monitoring and evaluation report for 2005 [Internet] (Loughborough, Institute of Youth Sport Available from http://www.lboro.ac.uk/iys [Accessed February 9th 2006]). 
Macbeath, J., Kirwan, T, and Myers, K, (2001) The Impact of Study Support: A report of a longitudinal study into the impact of participation in out of school hours learning on academic attainment, attitudes and school attendance of secondary school students. (London, HMSO).

Martino, W., \& Pallotta-Chiarolli, M. (2003) So what's a boy? Addressing issues of masculinity and schooling (Maidenhead, Open University Press).

Mcguire, B., \& Collins, D. (1998) Sport, Ethnicity and Racism: The Experience of Asian Heritage Boys, Sport Education and Society, 3.79-88.

Nike/Youth Sport Trust (2000) Girls into Sport: Towards Girl-Friendly physical Education (Loughborough, Institute of Youth Sport).

Office for Standards in Education (2002) The School Sport Co-ordinator Programme: Evaluation of Phases 1 and 2, 2001-2003 (London, HMSO).

- (2003) The School Sport Co-ordinator Programme: Evaluation of Phases 1 and 2, 2001-2003, (London, Crown Publications).

— (2004). The School Sport Partnership Programme: Evaluation of phases 3 and 4 2003. London: Office for Standards in Education.

- (2005b) The physical education, school sport and club links strategy: The school sport partnerships programme. Support for gifted and talented pupils in physical education (London, Crown).

Parker, A. (1996) The construction of masculinity in boys' PE, Gender and Education, 8.141-157. 
Penney, D. (2002a). Equality, equity and inclusion in Physical Education, In A. Laker (Ed.), The Sociology of Sport and Physical Education. (London, Routledge),

- (2002b). Gender and physical education : contemporary issues and future directions (xii, 230). New York: Routledge.

- (2002c). Gendered policies, In D. Penney (Ed.), Gender and Physical Education: Contemporary Issues and Future Directions (London, Routledge),

Penney, D., \& Evans, J. (1999) Politics, Policy and Practice in Physical Education. (London, E and F N Spon).

— (2002). Talking gender, In D. Penney (Ed.), Gender and Physical Education: Contemporary Issues and Future Directions (London, Routledge),

Penney, D., \& Harris, J. (1997) Extra-curricular Physical Education: More of the Same for the More Able., Sport Education and Society, 2.41-54.

Quick, S., \& Goddard, S. (2004). Schools in the School Sport Partnership Programme: PE, School Sports and Club Links Survey 2003-4. London: Department for Education and Skills.

Schools Competition Developments Bulletin 2 (2005). Schools Competition Developments Bulletin 2 [Internet]. Loughborough: Youth Sport Trust. Available from: http://www.yst.org.uk [Accessed 22nd November 2005]. Shah, A. (2003). Out of School Hours Learning: the views and opinions of the New Opportunities Fund Staff [Internet]. London: New Opportunities Fund. Available from http://www.nof.gov.uk [Accessed 22nd Nov 2005]. 
— (2005). Achievements and challenges in delivering out of school hours learning: final report [Internet]. London: New Opportunities Fund. Available from http:/www.nof.gov.uk [Accessed 22nd Nov 2005].

Skelton, C. (2001) Schooling the boys: masculinities and primary education (Buckingham, Open University Press).

Skelton, C., Francis, B., \& Smulyan, L. (2006) The Sage Handbook of Gender and Education (London, Sage).

Sport England (2004). The Equality Standard: A framework for sport [Internet]. London: Sport England. Available from: http://www.sportengland.org/equality_standard [Accessed 22nd November 2005].

Walby, S. (2000) Beyond the politics of location: the power of argument in a global era, Feminist Theory, 1.189-206.

White, A. (1997). Towards gender equity in sport: an update on sports council policy development, In A. Tomlinson (Ed.), Gender, Sport and Leisure (Aachen, Meyand Meyer Verlag),

Wright, J. (1996) The Construction of Complementarity in Physical Education, Gender and Education, 8.61-79.

Youth Sport Trust (2000) School Sport Co-ordinator Programme Handbook (Loughborough, Youth Sport Trust).

— (2005). Welcome Pack for School Sport Coordinators [Internet]. Loughborough: Youth Sport Trust. Available from: http://www:yst.org.uk/ssco/documents [Accessed 22nd November 2005]. 
